\section{Lessons from fisheries industry-led data collection efforts in the UK}

With many fisheries management organizations operating with lean budgets, finding funding to collect necessary data on how to properly manage fisheries can be difficult; let alone fill gaps in existing data collection efforts. In some instances in the UK, fishers have begun data collection projects of their own. To understand the reasoning behind and effectiveness of these projects, the authors investigated case studies engaging commercial fisheries with industry-led data collection efforts to supplement existing data sources.

Through reviewing the published literature, and surveying fishers and project leads, the authors found that industry-led data collection efforts typically arise in specific spatial areas where fishers are facing competition for marine space (for example, near wind farms or around marine protected areas). Such efforts may also arise due to scientific or management constraints which create economic drivers, as with the "categorisation of sharks, skates and rays as data limited stocks resulting in quota restrictions and fishing opportunities." The EU's Common Fisheries Policy is another example of an economic driver caused by management changes. The authors note that the "most successful initiatives were found to be the small and local, where the participants felt a commonality with the other participants." However, many of these initiatives were short-term, lasting only 1-2 years.

Longer-term data collection efforts typically had private funding at the beginning with public money being added later. "In general, project partners have been important in building credibility and ensuring buy-in to the results."

The authors found that fishers primarily engaged in data collection because of a sense of self-preservation or betterment. Data collection methods largely required either active or passive participation. Active participation required fishers to change their normal fishing activities to collect and share the data, including activities like tagging or measuring species, or identifying important nursery habitats. Passive data collections efforts were less hands-on, typically involving technology like CCTV or log/sensor data.

Sadly, the authors discovered that "the technical impact of the data collected has been relatively low." Though, the authors did find that in cases where there was buy-in from the fishing community, costs were low and benefits were high. Strong leadership from both fishers and scientists was also a key to success. Clearly communicating incentives to fishers, common ownership, and shared goals were also important. Soliciting and incorporating feedback was a factor of most successful initiatives, as fishers liked to hear that something was actually happening due to their efforts.

Generally, top-down approaches were not as successful. Funding issues, participate fatigue, and poor communication were evident in unsuccessful projects. Fishers commonly reported that data being used against them was a concern.
This is a summary of: Progress in designing and delivering effective fishing industry-science data collection in the UK

Accessible at: https://marxiv.org/p25a4

Authors: Stephen Mangi, Sven Kupschus, Steven Mackinson, Dale Rodmell, Alexandra Lee, Elizabeth Bourke, Tom Rossiter, Jim Masters, Stuart Hetherington, Thomas Catchpole, David Righton

Added to MarXiv:

April 2018

Published: Fish and Fisheries, 2018

Suggested Citation: Lessons from fisheries industry-led data collection efforts in the UK. OCTO (2018). DOI: 10.31230/osf. io/sy6pk

See more MarXiv summaries at https://www.marxivinfo.org/ summaries

Join the MarXiv Summaries monthly newsletter at https:// oct.to/marxivsum

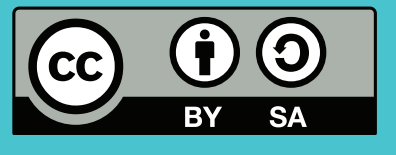

MarXiv is an ОСТO Initiative

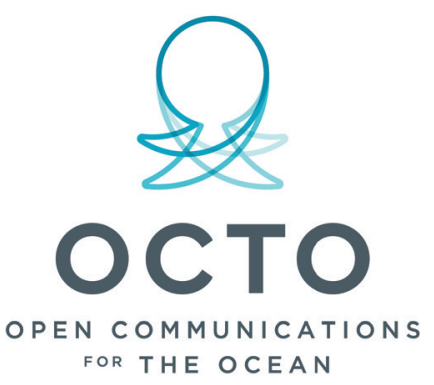

